\title{
CONTINUOUS AUDITING AS AN ELEMENT OF EFFECTIVE CORPORATE GOVERNANCE
}

\author{
Maksim Dmitrenko \\ Postgraduate student, Kryvyi Rih National University, \\ e-mail: m.k.dmitrenko@gmail.com, orcid.org/ 0000-0003-2553-7122, Ukraine \\ Andrey Matsegora \\ Leading auditor, PJSC "ArcelorMittal Kryvyi Rih", \\ e-mail: andrey.matsegora@arcelormittal.com, Ukraine
}

\begin{abstract}
The article deals with the features of the control methodology of continuous audit, its main principles, the advantages of creating an effective system of continuous audit and risk management of large companies.
\end{abstract} audit.

Keywords: Continuous auditing, automated indicator information system, internal

DOI: http://dx.doi.org/10.23856/2410

\section{Introduction}

The development of the world economy in modern conditions raises the problem of risk optimization with particular urgency. According to a research of Ernst \& Young, conducted in Europe, today the management of companies faces with more complex issues than ever before.

The wide spread of computerization of accounting promoted the development of works aimed to automate the audit process. The development of networksdata transmission allowed to organize remote interactive access of auditors to information about relevantevents and their results. All this opened the wayfor the implementation of continuous audit.

\section{Continuous Auditing as a tool of effective corporate governance}

The most valuable task is to improve the quality of the management level, which involves creating an internal control, audit and risk management. Moreover, as demonstrated by the practice of large companies, the most effective way is the construction of a single riskoriented system of internal audit and control, which includes three key strategic directions: improving;

- formation of a risk-oriented system of internal control based on the strategy of quality

- development and improvement of activities functionally structured system of internal audit (SIA) on the conditions of centralization;

- establishment of a monitoring mechanism for prevention of abuses in the financial and economic sphere through the integrated program. In the course of operational exchange of information, relevant information must be identified, recorded and timely transmitted in a form that allows auditorseffectively use it.

The most relevant method of internal audit, allowing to ensure a control procedure at all levels of management, to identify main risks and their acceptable level, to develop 
procedures and processes aimed at Identify and track changes, to demonstrate the importance of internal audit and compliance with ethical standards is a method of continuous auditing.

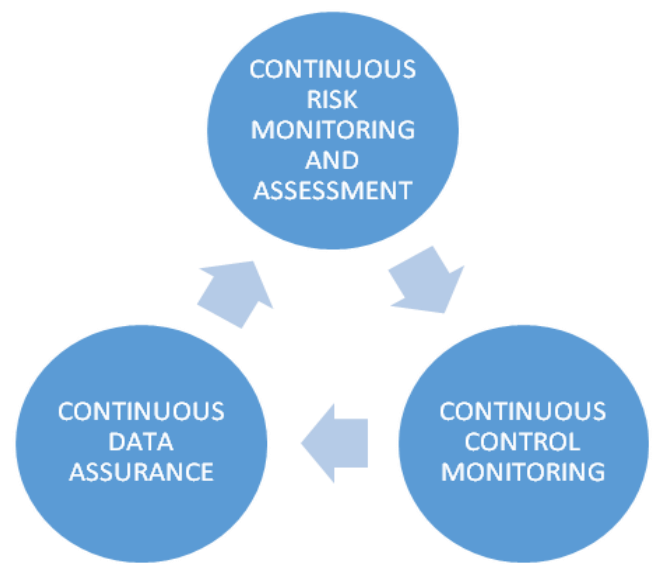

\section{Fig. 1. System of Continuous auditing}

Continuous auditing is an audit method in which all financial documents are evenly distributed which allows you to identify and correct errors before the end of the fiscal year. Continuous audit consists of three main parts:

- continuous data assurance (CDA);

- continuous control monitoring (CCM);

- continuous risk monitoring and assessment (CRMA).

CDA checks the integrity of data passing through the informationsystems. CDA also provides the extraction of data from IT systems.CCM provides the ability of continuously and automatically control

of operations, comparing them with pre-defined keyindicators for identifying abnormal situations. With a significant differences the "alarm" is triggered and information is sent to theauditors and stakeholders.

CRMA in real-time aggregates data for various types offunctional tasks, providing an integrated approach to evaluationrisks.

Intensity of deployment of continuous audit determines many factors such as characteristics of

economic sector, industry, enterprise, type of audit etc.

In particular, some parts of the information systems of organizations are more suitable forcontinuous audit than others. For example, the functional control areacash transactions one of the first candidates fordeployment of a continuous audit due to high level of automation and inherent risks. In general -the choice of functional areas fordeployment of a continuous audit depends on:

a) the importance of a higher frequency of audit for the area;

b) the opportunities provided by this area forautomatic control.

For example: regulation of monetary transactions. In most cases it is important to check the availability of positions and, at the same time, checking the availability of positions is automatically relatively simple, because money management systems are almost always highly automated. 
Also some branches of business are more amenable continuous audit than others. For example, the market of papers is almost completely automated andmany of the required data are almostspontaneously. In addition, rapid and unpredictable changesin the quotations of securities make such an auditespecially important for interested persons. Similarsituation is also formed in practically allnew "digital" economy.

To a large extent, the success of theaudit depends on financial (and other) advantages

of the audited organization and spending on implementation of audit. These costs can be divided

on direct and indirect.

Advantages for the audited organization include:

- the benefits obtained through the rapid identification of deviations and irregularities in activities of organization;

- the more optimal use of available resources of monetary and material resources;

- benefits derived from the reduction of number of on-site inspections and others related to control costs.

Direct costs include the cost of development (or acquisition), as well as the cost of commissioning a continuous audit system. The advantages for an audit firm are to reduce direct control costs, to constantly save labor costs associated with a routine audit, as well as to save travel expenses and time for face-to-face meetings etc.

The quality of the audit depends on a number of factors. So, the timeliness factor has big importance. The introduction of a continuous audit makes sense only when the results obtained by it are promptly in demand by the management of the audited organization and used by it for improving the quality of management, for reducing the costs of the organization, for increasing its revenues. Particularly well, if continuous audit not only reports timely relevant events, but also warns about their possible consequences. And the frequency of control is important not only for the audited organization, but also for other users of its financial information. For example, a higher frequency of audit of debt obligations, on the one hand, allows organizations optimally pursue their debt policy, and, on the other hand, debtors can more quickly prevent violations of debt agreements and take appropriate preventive actions.

A significant role also plays such factor as thoroughness. Continuous auditing is carried out automatically, which means that selective test typical for traditional audit is replaced by a continuous one. It allows to check all set of data related to the investigation area. In addition, the high frequency of checking of data stored in the RP and frequent application to the data of analyticalprocedures significantly reduces the risk of entry into the system erroneous data. It allows to detect in timesuch type of data.

A special place in the system of continuous audit has the reliability factor. On the one hand, automatic procedures are not as prone to errors as manual. Computers and software systems running on them (including those that implement continuous audit) are free from all distractions. They have developed systems for monitoring and eliminating errors. But, on the other hand, automation has a number of systematic risks. For example, if an error is made in the implementation of any computer procedure, then the results of this error are likely to be multiplied, which in turn will usually reveal such errors at the stage of trial operation of the system and correct them in time. Modern advances in software development allows to reduce the number of such errors to an acceptable level.

It is well known that the quality of an audit often depends on a moral factor, in many cases imperceptible to stakeholders. For example, the auditor may lack of motivation to apply 
enough effort necessary to ensure a high quality work. That is not about automatic audit procedures. They always do the work with the same efforts created by developers or auditors, who built the system.

The deployment of a continuous audit can improve the economic efficiency of enterprises, reduce the costs of institutions, increase the efficiency and effectiveness of resource management. It can manifest itself in various ways.

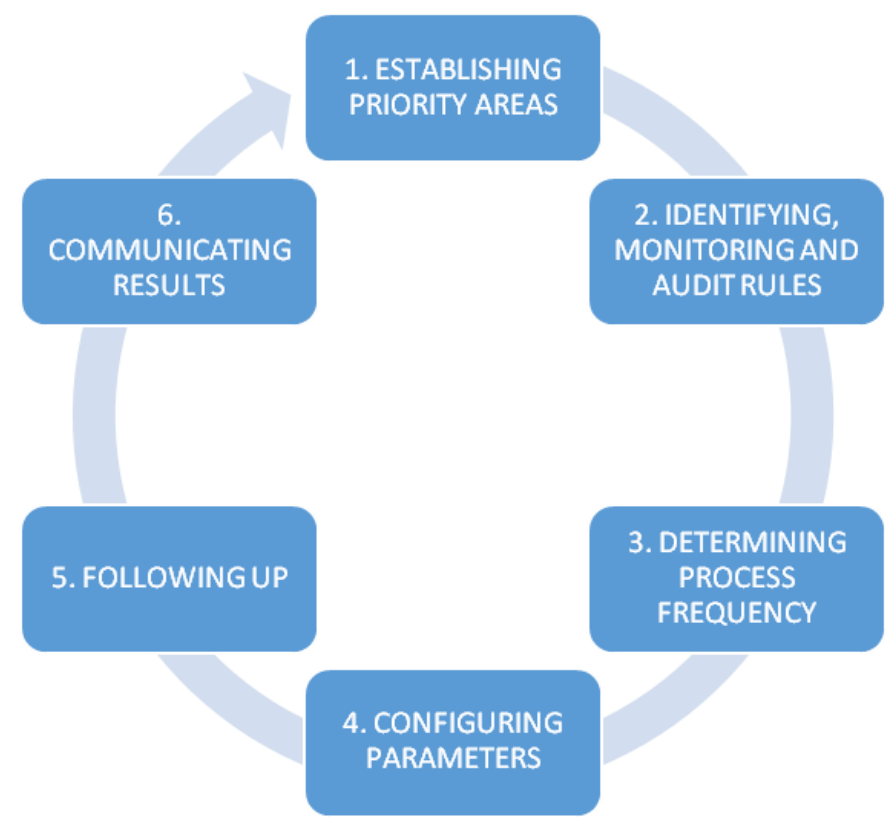

Fig. 2. CA implementation steps

(Six Steps to an Effective Continuous Audit Process, 2013)

A continuous audit system will undoubtedly has affect the behavior of the audited personnel organization. On the negative side, there can be considerable reluctance to accept a continuous audit due to the effect of the "big brother". Initially, work under constant supervision can cause undue strain on the staff. However, having felt that continuous audit is not a hindrance, but rather help in work, the staff is probably very soon get used to the fact that his actions are controlled in real time. On the positive side, the personnel of the audited organization, feeling that they are constantly monitoring their activities, will try more responsibly treat their work. At the same time, the level of trust in audited organization from persons outside the company will be increase.

Continuous audit allows in a short time and with low cost automatically to process huge amounts of information, analyze it, summarize and prepare reports reflecting the consolidated information in a form convenient for human perception. The ability to receive information about the real state of the organization, its financial and material resources (reserves), allows management to make informed and structured decisions.

A continuous audit can significantly affect the numerous external contracts of the audited organization. For example, it can ensure continuous monitoring of the execution of debt contracts and timely warn of possible violations of debt obligations. This will 
significantly improve the effectiveness of the organization's interaction with debtors, lead to significant changes in thedebt policy of organization.

The development of continuous audit provides opportunities for the development of continuous interactive reporting. Continuous audit allows generating the required reporting with any desired frequency. Such reports can include any parameters of accounting, for example, the current review of debt obligations, fixed and working capital, other variables. The frequency of issuing these reports is limited only by the frequency of the output parameters. The possibility of obtaining an interactive financialreporting is attractive to users of financial statements. It allows the management of the organization to more reasonably predict the development of activities and make informed decisions.

Obstacles to the implementation of continuous audit can be divided into two types: technical and organizational. Technical obstacles are caused because of complex development of such systems and high requirements to ensure their safety. The latter is especially important, because the interactive exchange of auditor with the RP of the audited organization goes through the using the Internet, which is not yet sufficiently protected todayfrom unauthorized access. The existing lack of appropriate security measures when using the Internet can prevent its wide use for the transfer of financial reports and other data required for remote audit. When conducting a continuous audit, it is also important to ensure reliable protection of the files used and have strict observance of standards and data security standards.

At the same time, the progress in the development of information technology, largescale studies in the area of audit automation make possible to conclude that the technical obstacles to the introduction of continuous audit will be overcome in the near future.

In addition to technical reasons, the main obstacles to the introduction of continuous audit are connected with the fear of the audited organization that continuous audit will make the activity of the organization too "transparent", will allow easy identify managerial failures and poor performance of personnel. Most of the arguments against the introduction of continuous audit are causedby these fears. Also, continuous audit requires that auditors have direct access to the information systems of the audited organization. Such access requiresa high level of trust between the auditor and the audited organization.

To develop a continuous audit in large companies, it is necessary to create an automated indicator information system for the continuous audit of financial and economic indicators (AIIS) integrated into the accounting systems of the company and allowing to determine the correctness of the planned parameters, regulatory and limit values by means of logical compliance settings. AIIS with the function of indicator system of will allow to mark the discrepancy with the indicator of any data and receive developed information.

In the digital analysis of AIIS, mathematical methods can be used:

- in the CDA to verify the integrity of data passing through information systems;

- in the CCM for continuous automatic control of operations by comparing them with predetermined key indicators for identify abnormal situations;

- in CRMA for data aggregation for various functional tasks, providing an integrated approach to risk assessment.

AIIS will be able to mark with a special badge illegal operations or operations that require additional clarifications, conducted on the accounting, tax programs: operations performed with excess of the established limits, contractualconditions, available powers, price and other restrictions imposed by the current regulatory enactments. The icons can 
havedifferent, according to the principle of the indicator, color or designation, depending on the type of violation and its significance.

In the AIS, you need to have a module that is tunable by various criteria on the produced business transactions, reflected in the RP and other software complexes. Such a module can control:

- company income;

- performance of qualitative indicators of the work of the units;

- compliance with depreciation rates for new funds;

- production of capital investments.

All the processed information can be saved and systematized for further use in order to optimize strategic risks, and management for the purposes of operational management. It seems that continuous auditing will first of all preventloss revenue of company and optimize risks in this sector.

Application of IT-technologies allows to minimize human factors. Due to new business conditions, a huge area of information, a desire to show the activities of their sub-divisions in the most positive light or other reasons, one and the same indicators are taken into account in different ways in different informationsystems, and as a result, information is distorted to the level when it is no longerpossible to use it for making managerial decisions.

The most common problems when entering data by personnel in the information environment are:

- input of incorrect information;

- entering the correct data in the wrong place;

- entering the correct data at the wrong time;

- approval of the wrong document;

- abuse, etc.

Practice shows that with less influence of the human factor on the input information, it is more reliable.

The introduction of a continuous audit and the corresponding AIIS not only allows to optimize risks and reduce losses to a minimum, but and performs a preventive function, since the head, who made a decision to conduct an illegal operation and can correct the error in a timely manner.

\section{Conclusions and suggestions}

Undoubtedly, the transition to continuous audit is a process not without obstacles, requiring new thinking about control and audit and their role in improving the activity of the audited organization. However, this transition brings to audited organization a number of benefits: a shorter control cycle, increased management flexibility, customizable reports and reports for the clientele and third parties, reducing the costs associated with the audit. For state audit bodies and audit firms, the use of continuous audit technology makes it possible to significantly expand the scale of their activities and its information security, devote more resources to analytical work to other services.

\section{References}

Alles, M., Kogan, A., Vasarhelyi, M. A. (2010). Accounting in 2015. The CPA Journal, November. [in English]. 
Christensen, B. E., Glover, T. C., Shelley, M. K. (2016). Understanding audit quality: Insights from audit professionals and investors. Contemporary Accounting Research, 33(4). [in English].

Coderre, D., Verver, J. (2006). Continuous auditing: implications for assurance, monitoring, and risk assessment. Institute of Internal Auditors, 1-10. [in English].

Demirkan, S., Zhou, N. (2016). Audit pricing for strategic alliances: An incomplete contract perspective. Contemporary Accounting Research, 33(4). [in English].

Kokemuller, N. (2011). The Advantages of Continuous Auditing. [Electronic resource]. Retrieved from http://small business.chron.com/advantages-continuous-auditing-39568.html. [in English].

Marks, N. (2012). Should internal audit perform continuous auditing? [Electronic resource]. Retrieved from http://normanmarks.wordpress.com/2012/06/15/should-internal-auditperform-continuous-auditing/. [in English].

Nigrini, M. J. (2013). Continuous auditing. Ernst \& Young Center for Auditing Research and Advanced Technology and Advanced Technology University of Kansas. [in English].

Peterson, J. (2016). Audit quality and the expectations gap. The CPA Journal, February. [in English].

Stippich, W. (2014). Continuous Auditing = Continuous Improvement. [Electronic resource]. Retrieved from http://www.corporatecomplianceinsights.com/continuous-auditingcontinuousimprovement/. [in English].

Teeter, R. A., Brennan, G., Alles, M. G., Vasarhelyi, M. A. (2008). Aiding the Audit: Using the IT Audit as a Springboard for Continuous Controls Monitoring, Working Paper, CarLab, Rutgers Business School. [in English]. 